\title{
A Practice-based Approach to Developing Creativity in Higher Education
}

\author{
Dr Andrea I. Frank, CEBE Subject Advisor for Planning; Lecturer \\ School of City and Regional Planning, Cardiff University \\ Email: FrankA@Cardiff.ac.uk
}

\section{Fred Buining, Creativity Advisor and Facilitator}

FredWerk, The Netherlands

\begin{abstract}
There is increasing demand for professional level creativity. In order to facilitate such professionally orientated creativity development through tertiary education we suggest that students need learning experiences different from those conventionally provided in Higher Education degree programmes today. This paper reports on an ongoing project which aims to introduce professionally orientated creativity development in the undergraduate planning degree course at Cardiff University's School of City and Regional Planning. The project represents a response to calls for education providers to equip planning graduates with creative problem solving and visioning abilities. Considering the professional profile of planners, creativity development focuses specifically on 'Creative Leadership' and 'Creative Urban Planning Intelligence'. The authors' efforts and experiences of introducing creativity development led to the creation of a forward looking curriculum model that combines old and new pedagogies and content. Progress toward implementing this model in Cardiff is traced and critically evaluated by sharing lessons from the first three years of experimentation, discussing different variations of intervention and their effects. Introducing changes in established programmes and curricula is difficult. Our experience demonstrates that the (nonconformist) collaboration between a lecturer and an expert creativity consultant employed in this project has been useful and stimulating in facilitating such changes.
\end{abstract}

Keywords: Creativity, Teaching Innovation, Curriculum Development, Urban Planning 


\section{A Need for Professional-level Creativity}

Creativity has been identified by individuals and scholars as the key to unlock intellectual potential necessary to address an array of complex problems faced by society, such as climate change, deprivation, or planning for sustainability (e.g. Dewulf and Baillie, 1999). Consequently, there is a growing demand for professionals to think creatively, and develop and design collaboratively innovative and novel solutions. From an educational perspective it is important to recognise that creativity is a complex and multifaceted concept (e.g. Dewulf and Baillie, 1999; Sternberg, 1999), which must be made specific to be meaningful. An engineer will likely characterise creativity differently than an artist or entrepreneur and particular aspects of creativity may be better suited to certain professions or tasks. In this paper, the field of (town and regional) planning is used as a case study to illustrate how such creativity needs can be specified and how their development can be integrated in a Higher Education curriculum.

Planning in the United Kingdom represents an interesting case as recent government directives have called for a change in planning culture (ODPM, 2001) broadening the current interpretation of the professional remit, which is centred on development control and statutory activities. In this new 'spatial' planning culture, planners are charged with space and place making to help deliver sustainable communities. The new focus requires planners to become leaders, social entrepreneurs and facilitators, who work in interdisciplinary settings to promote urban life styles that prevent the deterioration of the environment and enhance human quality of life. The development of alternative, sustainable settlement patterns requires specific skills such as forecasting (Cole, 2001), networking, collaboration as well as creativity (Higgins and Reeves, 2004; Albrechts, 2005). The implication for planning education is that students need to acquire creative and leadership competencies (e.g. Kunzmann, 1997; Royal Town Planning Institute 2003, 2004) alongside traditional professional knowledge.

But how can creative competencies be taught and developed (if at all) ${ }^{1}$ ? Planning education programmes are mostly offered through (research-oriented) higher education institutions ${ }^{2}$, which are typically not configured to develop creative competencies; rather they focus on students' knowledge acquisition and development of rational, analytical skills. Considering the long standing focus on social science based, rational planning and development control within the profession, there is a dearth of experience amongst teaching staff in how to promote students' creative potentials. Even design and studio instruction may be more constrictive and less imaginative than one might believe, as

\footnotetext{
${ }^{1}$ The debate on the teachability of creativity is covered in a wide-ranging literature. The authors believe that many aspects of creativity can be developed through training and exercises, i.e. creativity can be enhanced through teaching.

${ }^{2}$ Courses with a specific design or creativity focus such as music, art, architecture or creative media represent the exception rather than the norm.
} 
designers frequently adapt only past precedents without much innovation; nonetheless it may serve as a starting point (Hendry, 1991).

This paper reports on an experimental project in the undergraduate City and Regional Planning degree course at Cardiff University, that seeks to devise learning experiences that deliberately develop students' creative competencies in respect to professional level tasks. Considering the advances and expertise in creativity training in corporate professional development, the project engaged an expert creativity consultant with experience in organisational change and transformation to provide assistance in a) devising curriculum elements for creativity development and b) their implementation. This collaboration was not uncontested as it questioned and challenged traditional university teaching approaches, however, it also facilitates a development process of customised, planning specific creative thinking exercises. These exercises revolve around aspects of creativity that seem particularly relevant for planning and planners: 'Creative Leadership' (CL) and 'Creative Urban Planning Intelligence' (CUPI). We also realised that the culture change necessary to support effective creativity development in the planning school, or any other institution for that matter, requires repeated interventions, staff development and a tangible vision to work towards. We have developed, therefore, over the course of the project, a conceptual model curriculum. This model curriculum now informs and guides the further development of the project and the implementation of creativity development.

In detail, the paper will:

1. outline an emerging conceptual curriculum model for professional creativity development in higher education

2. identify creativity areas relevant for planning education and important conditions necessary in establishing and supporting a creative culture, giving examples of customised creativity development exercises, and

3. describe and evaluate the progress made in implementing the curriculum model at Cardiff University's School of City and Regional Planning.

Lessons drawn from the pedagogical experiments conducted in the past three years conclude the paper.

\section{Curriculum Model for Explicit Creativity Development}

According to the American Planning Association (2006) planning is a "dynamic profession that works to improve the welfare of people and their communities by creating more convenient, equitable, healthful, efficient, and attractive places". This involves "the management of competing uses for space, and the making of places that are valued and have identity" (Royal Town Planning Institute, n.d.). This is not easy. Planners need to develop a variety of analytic and creative thinking skills to balance different stakeholder needs and resource constraints and to find solutions that are both 
desirable and workable. Moreover, in order to fulfil sustainability goals increasingly promoted by many national governments, planners will need courage to look beyond tried and tested solutions. Planners will need to break the rules and develop new ideas (Sandercock, 2004). We believe that like analytical thinking, creative thinking that leads to novel solutions and processes can be improved by training and practice. Hence, education will need to provide students with the opportunities, the space and the techniques to develop their competencies, such as brainstorming, or lateral and divergent thinking (e.g. De Bono, 1992) and the planning curriculum should reflect this.

We have therefore started to outline a conceptual model curriculum which contains core elements designed for creativity development, fostering students' confidence in their own abilities to develop novel processes and innovative concepts for future urban living alongside traditional curriculum contents. Overall, we propose three module types:

a) Modules focusing on traditional subject knowledge and skills and cognitive rational learning outcomes (economics, planning processes and legislation, history of urban planning)

b) Modules focusing on creative learning outcomes and creativity development relevant to the professional profile of planning (e.g. enhancement of town character, or facilitation of group processes and idea generation)

c) Integrative modules that require students to apply creativity in realistic settings.

One might argue that a similar division of modules already exists in planning curricula. However, traditionally curricula tend not to designate learning outcomes explicitly as either cognitive rational or creative. In planning, creativity is mostly associated with physical planning, i.e. urban design and renewal (Town Planning Network, 1999, p 3), and creativity development is generally considered an implicit outcome of design modules. If we want as a profession to embrace creativity development, this needs to be changed.

Moreover, in our view, creativity development goes beyond the mere artistic aspect of design or what we call 'creative urban planning intelligence' to include 'creative leadership'. While CUPI seeks to enhance students' physical planning repertoire, CL addresses issues of social creativity and problem solving, working with interest groups and professionals. Our emerging model curriculum thus comprises of a more comprehensive set of creativity development as well as offering a balance of creative and analytical cognitive modules.

Table 1 depicts the model curriculum's structural makeup based on a three-year programme currently customary in England, Wales and Northern Ireland. Modules focusing primarily on rational knowledge and skills and modules focussing on creativity development are separated conceptually. Both module types are part of the core, 
meaning students are required to take at least one creativity development module per academic year as only repeated confrontation with creativity concepts ensures a lasting impact on students' development (Cropley and Cropley, 2000). In addition, each year a mandatory integrative module is offered, which combines creativity development and other knowledge acquisition through project work. Although the changes required to implement this curriculum model will inevitably reduce the time available for the acquisition of subject specific knowledge, other learning outcomes specified by the profession (RTPI, 2004, p 10) such as students' ability to "generate visionary and imaginative responses to planning challenges" will be strengthened.

Table 1: Three Year Undergraduate Model Curriculum Structure

\begin{tabular}{|c|c|c|c|c|}
\hline & \multicolumn{2}{|c|}{$\begin{array}{l}\text { Traditional Subject } \\
\text { Knowledge \& Skills } \\
\text { Development }\end{array}$} & \multicolumn{2}{|c|}{$\begin{array}{l}\text { Creativity development activity } \\
\text { development/Project Work }\end{array}$} \\
\hline \multirow[t]{2}{*}{ Year 1} & $\begin{array}{l}\text { Optional } \\
\text { Modules }\end{array}$ & $\begin{array}{l}\text { Core } \\
\text { Modules }\end{array}$ & $\begin{array}{l}\text { Core Module } \\
\text { e.g. Intro to creativity } \\
\text { concepts: individual } \\
\text { creativity versus } \\
\text { group/social creativity }\end{array}$ & $\begin{array}{l}\text { Optional } \\
\text { e.g. Basic facilitation } \\
\text { approaches } \\
\text { Application of } \\
\text { particular lateral } \\
\text { thinking techniques }\end{array}$ \\
\hline & \multicolumn{4}{|c|}{$\begin{array}{l}\text { Integrative Project I (embedding idea generation techniques and cumulative } \\
\text { decision patterns) }\end{array}$} \\
\hline \multirow[t]{2}{*}{ Year 2} & $\begin{array}{l}\text { Optional } \\
\text { Modules }\end{array}$ & $\begin{array}{l}\text { Core } \\
\text { Modules }\end{array}$ & $\begin{array}{l}\text { Core Module } \\
\text { e.g. Engagement with } \\
\text { professional aspects } \\
\text { of creativity }\end{array}$ & $\begin{array}{l}\text { Optional modules } \\
\text { e.g. Advanced } \\
\text { facilitation } \\
\text { approaches and } \\
\text { training }\end{array}$ \\
\hline & \multicolumn{4}{|c|}{ Integrative Project II (embedding CUPI and CL techniques) } \\
\hline \multirow[t]{2}{*}{ Year 3} & $\begin{array}{l}\text { Optional } \\
\text { modules }\end{array}$ & $\begin{array}{l}\text { Core } \\
\text { Modules }\end{array}$ & $\begin{array}{l}\text { Core Modules } \\
\text { e.g. Creativity and } \\
\text { research }\end{array}$ & $\begin{array}{l}\text { Optional modules } \\
\text { e.g. Specific } \\
\text { creativity tools, } \\
\text { such as TRIZ }\end{array}$ \\
\hline & \multicolumn{4}{|c|}{ Final Integrative Project III or Research Thesis } \\
\hline
\end{tabular}




\section{What Kind of Creativity for Planners?}

Sandercock (2004, p 134) suggests that planning skills required in the $21^{\text {st }}$ century differ markedly from those promoted in $20^{\text {th }}$ century planning education, while Landry (2000) determines that we certainly cannot solve $21^{\text {st }}$ century problems with $19^{\text {th }}$ century technology and approaches. Similarly, Albrechts (2005, p 262) suggests that planners for "too long have just been trained to react to problems and difficulties" and tend to focus on reproducing answers on the basis of previous solutions. Even in the design profession (urban design but also architecture) there can be a heavy reliance on repeating and adapting precedents and patterns that have worked in the past. In many cases, there is nothing necessarily wrong with this and it would be foolish and inefficient to invent new ways of doing things constantly. However, when we are searching for approaches to make our communities more sustainable and live in different ways, we require structurally different futures. In order to develop true innovation we need to challenge old patterns of responses, or in the words of Sandercock (2004, p 136) planners need dare "break the rules" and create new solutions. We need to look at problems from different angles and perspectives and make new connections. This is not easy and requires imagination, persistence and taking risks (Landry, 2000). Initially, new ideas may be treated with scepticism, as for example, Howard's novel concept of the Garden City, which was ahead of its time. While some of us have a divergent thinking approach, many of us require training to learn how to break our traditional thinking patterns and move to new ideas.

Another, related aspect is that planners in many cases see themselves as technocrats rather than leaders. However in order to promote new visions, sustainable development or different transport options, planners need to be willing to lead and spearhead a transformative agenda (Friedmann, 1987). Either aspect, i.e. developing methodically and systematically innovative solutions and the art of leadership are not customarily focused on in the planning curricula that the authors are familiar with and appeared to us the most promising areas for creativity development in our experimental project.

\section{Creative Urban Planning Intelligence}

Intelligence in a discipline means not only to master theoretical and practical knowledge (rational, cognitive, conscious ...) but also to be aware of subjective signals, emotions and the subconscious. Students need to develop multiple ways of understanding the city. An awareness of the physical patterns and interdependencies between various development scales such as neighbourhoods, towns, regions and their constituting elements of buildings, streets, open space and transport networks needs to be complemented with an understanding of urban governance and how history, economy and interactions of people form the character of spaces and places.

In a way, cities can be compared to texts; like words and punctuation, buildings, squares, streets and voids can be put together differently and become either poetry or 
prose, or non-sensical jibberish. Similar to writers, planning students need to become skilled in arranging urban elements to create environments. It is important to note that planners are rarely single authors. Rather, they act as editors or translators working in teams and communicating with a range of other professions involved in the creation, transformation and management of the built environment. Therefore they not only have to learn their own language, but need to understand different professional languages and must be able to 'translate' between them. According to Carmona et al. (2003, p 10) vision, hearing, smell and touch all contribute to creating a sense of place. Thus, students will need to hone all senses to create places that are social and human (see also Sandercock, 2004, p 134). Developing creative urban planning intelligence means to develop an understanding for the different languages in which we converse about the city, including the sensory, non-rational and emotional. It is about design but also goes beyond, embracing strategic planning.

\section{Methods and tools to enhance urban planning intelligence}

We have devised two sets of exercises to help students become conversant in different urban 'languages' and hone their senses beyond those of the rational and analytical. They are designed to systematically expand students' language vocabulary using various stimuli for the creative process, as well as for representations and outcomes. They built on exercises developed by others on lateral and creative thinking (e.g. De Bono, 1992) yet have a clear subject-specific focus. The first set (see examples A-C) develops students' creative abilities by confronting them with unconventional sensory input information, or output requirements that need to be translated into, or from a whole, or a detail of an urban plan.

\section{Exercise Set One: Sensory stimuli and triggers}

A. Sound: Students are assigned a building site on which to design housing for 100 households. They also are provided with a piece of music (classic, rock, folk, etc.) that serves as a stimulus. Designs should be inspired by the music and should reflect what the music means to a student.

B. Images/Emotions: Students receive images of urban scenes selected to evoke an emotional response. The assignment is to write a poem or lyrics for a song that reflects this emotion and describes the urban situation or an aspect thereof.

C. Sense of Smell: Students receive a sample of a perfume, which serves as the clue to the character of a part of a town. Students are to describe the character by outlining probable land uses (i.e. residential, industrial, nature etc.). They are encouraged to use any kind of media to express their ideas including text, collages, or sketches to create a visual representation of the place's character as imagined by the scent. 
The second set (see examples D-F) focuses on expanding students' 'urban language' repertoire.

\section{Exercise Set: Language repertoire}

D. City of professionals: Students are given a figure ground plan of a city devoid of functional information. They are asked to describe various professions (e.g. architects, economists, gardeners, traffic engineers) and to divide the urban space into areas defined by the dominant ideas of that profession. The resulting plan of the city should show clear differences between the 'professional neighbourhoods' and devise solutions for the border areas (transition zones).

E. Circle of life: Every person experiences a life cycle from infancy via middle age to old age. The assignment is to design a holistic urban plan in which all aspects of these life stages become visible. Students must describe the areas and show the difference in transport options, type of residences, use of nature and so forth.

F. Value and form: Form not only follows function but also embodies values. Planning students ought to be aware of these connections. For example, freedom of access and democracy is expressed through spaces without barriers and fences - and circular shapes (as in parliamentary debating chambers). To invoke reflection about values and form, students are asked to develop a list of values important for modern cities. Then, students must design urban elements that incorporate selected value in shape, form and use of materials, e.g. the Park for Families, the Public Square of Freedom etc.

These exercises can feel rather abstract and removed from what students' think they need to learn and care must be taken to explain their purpose. Explanations and links with the profession may be given beforehand, or revealed during debriefing when discussing the exercise results. The exercises can be employed in different settings. We have for example, employed an adaptation of exercise $E$ repeatedly to good effect in a first year project and design module. Rather than asking students to develop a holistic plan, individuals are assigned a role (elderly person, youth, or family parent) and use the interests of this role to describe preferable uses, transport options, character for a particular development site. In a second stage, students are asked to compare their criteria and lists and discuss synergies and conflicts. The object of the exercise is that students consciously and deliberately develop many different ideas by taking a variety of perspectives; by then discussing conflicts and synergies, new solutions often emerge.

\section{Creative Leadership}

Discussions about values and professional ethics represent a significant element in planning education. A planner's work lies in the public sector (even if they work for a 
private consultancy) and they have to evaluate and balance the needs of different stakeholders in development decisions. Being a planning professional not only means to be well spoken in discipline-specific languages but also to be a good listener. Furthermore, planning students need to become aware of their influence and role as facilitators and translators within the planning process. This awareness will help them to become less fixed on a single project or output and more focussed on the process of working continuously to improve the urban environment. As plan implementation is more successful if stakeholders (community members, businesses, minorities, service providers, builders etc) agree on a solution and take ownership, planners need to be able to facilitate social creativity, i.e. provide leadership in empowering the community to contribute to plan development. The ability to elicit, harness and focus the diversity of intellectual capital and goodwill amongst interested parties towards an agreed solution is a vital competency for planners.

Developing creative leadership through practice allows students to grow into responsible professionals and relate to community stakeholders in meaningful ways. Empowered leadership revolves around students a) understanding their own role in creating added value, b) being able to guide discussion among interest groups and c) to facilitate decision and plan making in collaboration with other professionals and stakeholders.

\section{Methods and tools for stimulating empowered leadership}

Creative empowered leadership is stimulated through carefully choreographed interactions between students or between students, staff, professionals and community members on planning related issues. Some exercises are designed to stimulate reflection - others to develop and practice students' facilitation expertise. The overall idea is to strengthen students' self-awareness of their own values and ideas and their confidence in the power of collaborative group working processes. They also need to gain confidence in their ability to guide decision making and visioning activities. In practicing facilitation in a supervised environment they hopefully learn that they need not solely rely on their own knowledge but can work with and shape decisions through the contributions and expertise of others.

Subject-specific induction This intervention should occur fairly early in the programme over a concentrated period of time (e.g. a weekend or several consecutive days). Unlike the standard university induction, here, first year students engage in discussions led by senior students on the future of planning, the needs of stakeholders and how that relates to their own areas of interest. Following this, students are asked to form teams and prepare questions for staff members and invited guest speakers from practice, governmental agencies, or citizens' organisations who are participating in the activity by giving presentations on urban problems or research. Students' questions must specifically address the future of the discipline and relate to students' interests. Questions should have two parts: argument and a related (set of) question(s). For the 
final session of the event, student teams supported by senior students have to prepare a presentation to teaching staff outlining the future of planning and their professional development plan for the years to come. At this stage students can be asked to sign their individual plans thereby committing to developing and investing time in their area of interest. Plans will be reviewed on an annual basis with a mentor. Aside from meeting staff and older students, the exercise forces students to reflect on planning, their interests and potential contributions. It creates a sense of shared leadership in the discipline and gives senior students an opportunity to help others in developing their views and to use their skills and knowledge in a serving and collaborative way.

Peer-learning Throughout the programme students are asked to engage in peer support activities, e.g. second year students will support the induction for first year students and fourth year students are supporting first and second year students in their studio work. One concrete example of such activities may be a show and tell by advanced students for students in the first year, showing them examples and relating how they started working. We tried this out recently with Master students showing their work to first year students. The learning effect was profound. The first year students seemed very open to the advice from the more experienced students and the Masters students reflected on how they have progressed over this time when seeing the shyness and inexperience of first year students.

Community based studio Every year students and staff engage in a project or projects that will serve a community in the vicinity of the university. Students may be asked to develop a plan or vision on a theme such as sustainability, or transport selected by the community. As students gain experience they will take more responsibility and work more independently with the community. Community engagements are not without problems (Kotval, 2003; Forsyth et al., 2000) and require significant staff commitment and careful management of expectations. However, such projects can also help students develop a sense of purpose and responsibility. It will also allow them to hone their facilitation and leadership skills. One particular exercise may be to let students set the criteria for the project and its evaluation/assessment. So for example, in a project on sustainability, students would need to investigate to what extent sustainability is to be incorporated in the project (assessment) and how could sustainability be developed more within the project, its approach and end result (recommendations). As sustainability has many different dimensions, students need develop (potentially with the stakeholders) a set of criteria. Any choices are political and there needs to be a discussion on the values and norms that are involved in making certain choices. The students will be evaluated on the aspects of being able to facilitate a stakeholder discussion and leading the development of these criteria within the project. 


\section{Conditions supporting creativity}

Creativity development is only achievable by providing suitable institutional conditions. Establishing these conditions has its own dynamics. Some conditions can be established within a department or school, such as specific assessment systems for creative work; others depend on institutional policies, such as staff development or reward structures.

\section{Communicating clearly about creative work}

The new curriculum model offers a spectrum of modules focusing on either analytic/knowledge-based or creative learning outcomes. Therefore it is important that foci are clearly communicated to students and are reflected in the assessment criteria to highlight the distinctiveness of learning. Research suggests that students express their creativity only if they feel it is desired and acknowledged in assessment (Town Planning Network, 1999). Therefore different grading and assessment schemes are necessary. Modules focusing on rational knowledge and skills employ a logical and rational grading system, meaning good grades can be obtained by studying and mastering tangible knowledge and processes from literature and practice. The better work aligns with state of the art knowledge, the better the grade. Modules emphasising creativity development require a different marking system. Although students follow certain rules related to a creative process, judgement of the level of creativity of the outcome (project, strategy, or plan) depends on the experience and values of the teacher and arguments of the student(s). For modules combining rational cognitive and creative work, a combination of cognitive rational and creative criteria should be employed and ideally marked by different staff members.

Finally, transcripts and diplomas should show not only the overall mark and degree, but detail the classification of modules into cognitive rational and creative knowledge and skill development, providing additional information to future employers about the qualities of a particular student. Students' choices over the course of a degree will document a greater affinity of either rational cognitive knowledge or creativity. Naturally, courses emphasising rational knowledge and skills provision are more comparable between universities; whereas creative development aspects provide a unique quality of a particular university.

\section{Professional growth of staff}

When involved in creativity development, teachers need to act as role models for attitude, behaviour, and facilitation of collaborative learning processes. Thus, similar to student-centred learning, teachers assume a role which is markedly different from the traditional where they act as an expert disseminating knowledge. As individual staff members have different affinities, they can develop either rational or creative aspects of the curriculum. Promotion procedures do not discriminate and individuals receive appropriate skills development whatever their preference. 


\section{Working with practice}

Creativity development activities have strengthened the school's connections with practice. CUPI exercises require students to investigate and research communities, neighbourhoods and cities. Thus, students are encouraged to interact with community groups to learn about their views and way of thinking. Guest speakers from various planning fields are regularly invited to contribute to classes, provide case material and assignments. Through the annual community-based projects of first and final year students, planning authorities can benefit directly from the students' work. Conversely, students can meet potential employers and job offers are not uncommon results of successful projects. New relationships are fostered each year during the school's open house/barbeque when students showcase work and future employers and citizens can learn about the school's activities.

\section{Progress toward an Ideal}

The introduction of creativity development in an existing curriculum is not easy. The project started in the academic year 2004/5. Throughout the three years of this ongoing project at Cardiff University's School of City and Regional Planning, the authors employed an incremental and dynamic approach. Reflection on the results of creativity development exercises used in one year informed and shaped the implementation of the exercises in the coming years, their future development, as well as our ideas for a model curriculum and the supporting institutional conditions for explicit creativity development described above.

\section{First steps - 2005}

At the outset of the project, a first year introductory module on physical development and land use planning was used as a pilot for the introduction of generic ${ }^{3}$ and customised creativity development exercises (CUPI). In the past, this module combined knowledge acquisition with the provision of transferable skills such as drawing, basic analysis and documentation. Creativity techniques were presented as one of many transferable skills that students were to acquire. The final coursework asks students to apply knowledge and skills they learned, to produce a conceptual design and layout for a new neighbourhood. The idea was that creativity development would be helpful for students to develop original design solutions.

In particular, students were introduced to creativity concepts by the consultant to give the subject credibility and make up for lack of experience in this matter by in house staff. Two, two-hour sessions on concepts of creativity, attitudes, processes and basic techniques were followed by a two-day weekend retreat at a remote hostel for further creativity development and design work. During the retreat, students worked in groups

\footnotetext{
${ }^{3}$ Generic techniques are brainstorming, six thinking hats, guided imagination etc. (see for example De Bono, 1992)
} 
to develop a neighbourhood design scheme. For most students this was the first time they were engaged in design work at such scale and many of them found it difficult and challenging. Each team of five to six students was supported by a tutor (staff who had received some limited training in the creativity techniques beforehand) and creativity techniques were interjected at strategic stages to help each group think more broadly (different styles of brainstorming) and stimulate lateral thinking by reversing their initial assumptions to develop alternative solutions. The intensity of the programme and long working hours spent in developing neighbourhood designs represented a new learning experience.

By the end of the weekend all teams successfully developed a conceptual masterplan. Several original ideas emerged and were incorporated in the designs such as the development of an ecological village with a community farm, or taking advantage of (rather than avoiding) sloping ground for recreational activities such as a BMX or motocross. In evaluations, students identified "being creative", "making plans", "developing ideas", "developing a concept" and "working as a team" as their top five learning achievements for the weekend. They found some of the instructions provided by the consultant confusing, but enjoyed his involvement and input nonetheless. Feedback from staff was also positive, although those usually involved in teaching urban design critically questioned whether the consultant's creative thinking prompts were an aid or a hindrance. Some staff members consider design as inherently creative and therefore see no need to enhance it with creativity techniques using analogies, metaphors or the like. Students clearly struggled to get to grips with drawing and representing their ideas graphically while responding to prompts by the consultant. However, the challenge appeared to also spur innovation in the groups. As this was a new module, designs could not be compared to previous years' results to judge the impact of the creativity interventions.

\section{Reflecting - 2006}

The creativity development sessions within the pilot module were repeated, albeit the consultant's input was reduced to two, two-hour sessions. Creativity concepts were introduced and techniques were applied for a small design task rather than the largescale assignment. Students were asked to create a mug design for the school's anniversary. Students were given different catalytic thinking tasks (e.g. informing the design through the images of a story, representing opposites etc) to help expand their vocabulary of ideas. Although many students initially felt embarrassed about their drawing abilities, stating they had "no ideas" all managed to develop graphics and ideas after just 80 minutes of coaching.

Respecting fellow staff's reservations about the consultants' involvement in the retreat weekend, more traditional approaches were employed to guide students' design efforts. Although the authors do not entirely agree with the notion that design is inherently creative, we concur that it may be best if students develop a basic approach 
to physical design and project work first. To stimulate some divergent thinking, students were assigned stereotypical stakeholder roles (environmentalists, family, old couple etc) before being placed in a team made up of a stakeholder mix. We hoped the different goals and ideas associated with these stakeholders would initiate a dialogue over values and preferences on how to develop the neighbourhood. The process was conceptually less challenging or confusing. Disappointingly, discussions to incorporate converging ideas from the different stakeholder perspectives quickly faded in order to get one solution on paper. Overall results were less imaginative compared to 2005.

In terms of the implementation of creativity development, the school has not adopted any binding strategy. However, some staff members involved in the 2005 activities started to explore creativity within their own teaching. One senior staff member, for example, introduced a 'blue sky' strategy project in his second year class. His evaluations suggest that students learned from their year one experience, as they took enthusiastically to this second opportunity to express their creativity. It will be interesting to compare future cohorts when they are subjected to their second creativity challenge.

\section{Gaining momentum - 2007 and beyond}

Gradually more creativity development is being introduced in the curriculum. For example, first year students have now an induction (weekend rather than a full week) only two weeks into their first term. Activities during this weekend include discussions on planning issues as well as professional development planning, however, without involvement of senior students. We have further refined the sequence of introducing creativity techniques in the first year integrative module. In particular, we are have involved a client and produced initial designs during a weekend charrette on site. The creativity consultant was brought in a week later to introduce various group working and CUPI exercises to help students improve on their design. We are also trying out new ways of evaluating the effectiveness of our pedagogical interventions by testing groups of students for their creative thinking abilities at the beginning and end of the term. The second year 'blue sky' project work will also be repeated.

At this stage, we have not yet introduced any creativity development in years three and four of the curriculum, although we have some ideas on what could be done. Implementation is dependent on the ability of other staff members to engage with the topic and we expect that winning more supporters will take several years. Table 2 shows how we envision adapting the model curriculum for the BSc City and Regional Planning degree programme in Cardiff in the longer term. Basic parameters of the original degree programme remain unchanged with three years of taught provision and a sandwich year (between years two and three), during which students are exposed to practice by working for a local authority or planning consultancy. 
Table 2: Vision for Planning Curriculum at Cardiff in 2012*

\begin{tabular}{|c|c|c|}
\hline & $\begin{array}{l}\text { Traditional Subject Knowledge \& } \\
\text { Skills development }\end{array}$ & Creativity development/Project Work \\
\hline \multirow[t]{2}{*}{ Year 1} & $\begin{array}{l}\text { Economic Issues in Spatial } \\
\text { Planning } \\
\text { Concepts of Spatial Planning } \\
\text { Stats and Information Systems } \\
+ \text { Options** }\end{array}$ & $\begin{array}{l}\text { Induction week (CL) } \\
\text { Society, Diversity and Planning (Set } 1 \\
\text { exercises e.g. circle of life exercise, CUPI) } \\
\text { Option: Facilitation + creativity tools (CL) }\end{array}$ \\
\hline & \multicolumn{2}{|c|}{$\begin{array}{l}\text { Integrative Module 1: Introduction to Concepts of Physical Planning and } \\
\text { project work: Master Planning Exercise - results presented to community } \\
\text { representatives }\end{array}$} \\
\hline \multirow[t]{2}{*}{ Year 2} & $\begin{array}{l}\text { Issues in Local Government } \\
\text { Environmental Policies \& } \\
\text { Planning } \\
\text { Research Skills (include GIS) } \\
\text { Planning Policy and Control } \\
+ \text { Options }\end{array}$ & $\begin{array}{l}\text { Site Planning and Development (Set } 1 \\
\text { exercises: e.g. city of professionals, CUPI) } \\
\text { Option: Participation in either Induction } \\
\text { week or Integrative Module } 1 \text { (CL) } \\
\text { Option: Sensual awareness workshop } \\
\text { (Set } 2 \text { exercises, CUPI) }\end{array}$ \\
\hline & \multicolumn{2}{|c|}{ Integrative Module 2: Planning, Markets and Land (strategic focus) } \\
\hline $\begin{array}{l}\text { Year } 3 \\
\text { Placement }\end{array}$ & \multicolumn{2}{|c|}{$\begin{array}{l}\text { Personal and Professional Development Planning (use mind mapping or } \\
\text { similar software to express personal development); potentially students could } \\
\text { be asked to organise either a group exercise on creativity or work on a project } \\
\text { with their employer }\end{array}$} \\
\hline \multirow[t]{2}{*}{ Year 4} & $\begin{array}{l}\text { Planning Theory and Practice } \\
\text { Planning Law } \\
\text { Rural Society and Planning } \\
\text { Transport Planning \& Travel } \\
\text { Behaviour } \\
\text { Research Paper or Project } \\
+ \text { Options }\end{array}$ & $\begin{array}{l}\text { Creativity in Research } \\
\text { Optional: Participation in either Integrative } \\
\text { Module } 1 \text { or } 2 \text { or Induction week } \\
\text { Option: Specialist Creativity Seminar }\end{array}$ \\
\hline & \multicolumn{2}{|c|}{$\begin{array}{l}\text { Integrative Module 3: Contemporary International Planning (international } \\
\text { dimension, urban project) }\end{array}$} \\
\hline
\end{tabular}

* Note: curriculum is a vision of the authors at the time of writing (not approved for implementation by the School)

** Option modules depicted in italics 


\section{Discussion and Conclusion}

The provision of creative planning professionals has gained new urgency in the UK due to a government induced change in the remit and culture of planning. This poses a challenge for educators who for decades focused on development control and social science based approaches to planning in their teaching. A partnership between a lecturer and a creativity consultant has been useful in facilitating creativity development in an undergraduate curriculum and accessing much needed expertise and practical experience not readily available within the discipline. The collaboration resulted in the development of a vision for a model curriculum that offers a balanced provision of modules focusing on creativity development alongside traditional subject specific content. It also provides staff development and led to the design of subject-specific creativity development exercises (CUPI and CL).

Curriculum change requires patience and the authors acknowledge that present activities in terms of culture change are in their infancy. Thus far implementation has been incremental and opportunistic (rather than calculated and strategic), meaning that creativity development activities were incorporated in modules that were under the control of interested staff. The first year pilot module in physical planning is representative of this approach. Nonetheless, the approach works well as it is compatible with academic management philosophies respecting lecturers' diverse interests and affinities, which may lie outside the creativity agenda.

The implementation of creativity development itself can be testing. For example, introducing a sequence of creativity thinking exercises to first year students is appealing. Theoretically this allows students maximum time to explore and use these techniques in subsequent years of study. However, first year students are just beginning their socialisation into the discipline and staff involved felt that students first needed a grounding in the discipline and the methods and tools conventionally employed by the profession before asking them to think creatively and develop unconventional solutions. The notion, whether right or wrong, is that an individual needs to be aware of conventions first before s/he can start breaking them. In the pilot module we have experimented (so far) with unconstricted creative thinking (2005) and a more structured, bounded approach (2006 and 2007); although in 2007, we allowed students to work more independently with less direct tutor involvement in the design groups. It is likely that several further iterations are required before we find a way to introduce students to creativity concepts and exercises with which colleagues feel comfortable and that optimally support the learning objective of giving students a grasp of creative thinking techniques.

In part due to the opportunistic implementation strategy, creativity development is currently provided almost exclusively within integrated modules using creative urban planning intelligence exercises. With the exception of the induction weekend, creativity development in empowered leadership is still weak. We have not had the opportunity to develop a freestanding creativity module and it will be a matter of debate if such an 
approach is desirable in the context of developing professional creativity. Measures to evaluate the impact of these initial interventions as well as guidelines for the assessment of creativity need also still to be developed.

The involvement of an outside expert consultant for curriculum change and creativity development is neither uncontroversial nor cheap. However, it has certainly been a source of new ideas and is constantly challenging traditions. Plans are to continue to involve the consultant at least in the years to come. The involvement of the expert helps to build capacity for creativity development instruction amongst staff members. Creativity training is commonplace in many industry settings and it would be ill-founded pride not to draw on this knowledge for the students' benefit. Activities need to be adapted for use in higher education, but by debating views and collaborating in efforts, celebrating improvement and acknowledging mistakes, we can be role models for future generations of creatively minded people and innovators in planning and other disciplines.

\section{Acknowledgements}

The authors are grateful for the Cardiff University teaching innovation grant that enabled and supported the work on introducing creativity development in the planning curriculum. 


\section{References}

Albrechts, L. (2005) Creativity as a Drive for Change. Planning Theory, 4 (3), 247-269.

American Planning Association (APA) (2006) What is Planning?

http://www.planning.org/careers/ (accessed September 2007).

Carmona, M., Heath, T., Oc, T. \& Tiesdell, S. (2003) Public Places, urban Spaces: The dimensions of Urban Design. London: Architectural Press.

Cole, S. (2001) Dare to dream: Bringing futures into planning. Journal of American Planning Association, 67 (4), 372-383.

Cropley, D. H. \& Cropley, A. J. (2000) Fostering creativity in engineering undergraduates. High Ability Studies, 11 (2), 207-219.

De Bono, E. (1992) Serious Creativity. London: HarperCollins Business.

Dewulf, S. \& Baillie, C. (1999) Case: how to foster creativity. London: DfEE.

Forsyth, A., Lu, H. \& McGirr, P. (2000) Service learning in an urban context:

Implications for planning and design education. Journal of Architectural \& Planning Research, 17 (3), 236-259.

Friedmann, J. (1987) Planning in the Public Domain. From Knowledge to Action.

Oxford: Blackwell.

Hendry, J. (1991) Design in the town planning curriculum. Design Studies, 12 (2), 114117.

Higgins, M. \& Reeves, D. (2004) Creative Thinking Tools for Planners and related Built Environment Professions. CEBE Working paper 04. Online.

http://www.cebe.heacademy.ac.uk/publications/workpapers/pdf/WorkingPaper 04.pdf (accessed October 2006).

Kotval, Z. (2003) Teaching experiential learning in the urban planning curriculum.

Journal of Geography in Higher Education, 27 (3), 297-308.

Kunzmann, K. (1997) The Future of Planning Education in Europe. AESOP NEWS, Summer 3-6.

Landry, C. (2000) The creative city: a toolkit for urban innovations. London: Earthscan. Office of the Deputy Prime Minister (ODPM). (2001) Planning: Delivering a fundamental Change. London: ODPM.

Sandercock, L. (2004) Towards a Planning Imagination for the $21^{\text {st }}$ century. Journal of the American Planning Association, 70 (2), 133-141. 
A.I. Frank \& F. Buining: A Practice-based Approach to Developing Creativity in Higher Education

Sternberg, R. J. (Ed.) (1999) Handbook of Creativity. Cambridge: Cambridge University Press.

Royal Town Planning Institute (RTPI). (n.d.) What planning does.

http://www.rtpi.org.uk/what planning does/ (accessed 18 April 2007).

Royal Town Planning Institute (RTPI). (2003) Education Commission Report. London: RTPI. http://www.rtpi.org.uk/download/236/Education-Commission-Final-Report.pdf (accessed 6 September 2007).

Royal Town Planning Institute (RTPI). (2004) Policy Statement on Initial Planning Education. London: RTPI. http://www.rtpi.org.uk/download/237/Policy-Statement-onInitial-Planning-Education.pdf (accessed 6 September 2007).

Town Planning Network. (1999) Creativity in Town Planning. London: University of Westminster. 